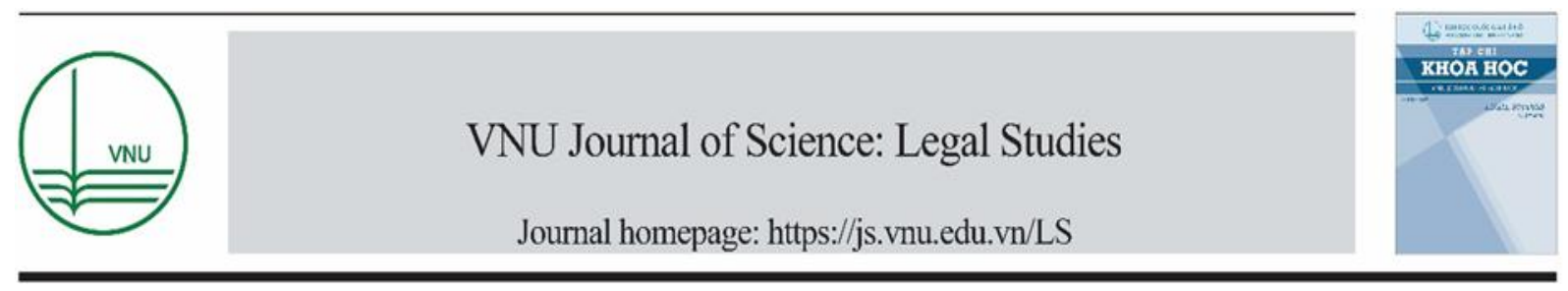

Review Article

\title{
Project-Based Learning Promotes Students' Motivation and Attitudes
}

\author{
Mai Hai Dang* \\ VNU School of Law, 144 Xuan Thuy, Cau Giay, Hanoi, Vietnam
}

Received 31 December 2020

Revised 03 March 2021; Accepted 26 March 2021

\begin{abstract}
This study examines how Project-Based Learning (PBL) influences the attitudes and motivation of law students in School of Law, VNU to learn the module International Envirnomental Law. The sample is taken by 100 students from School of Law, VNU. The study used a mixed methods research design: quantitative as well as qualitative. The two research hypotheses were as follows: 1) Does Project-Based Learning increase motivation in learning of students?; and 2) Does Project-Based Learning improve attitude for learning of students? The study's findings indicate that an intervention that combines the teaching of International Envirnomental Law with Project-Based Learning results in both increased motivation among students and more positive attitudes towards studying International Envirnomental Law.
\end{abstract}

Keywords: International Envirnomental Law, project-based learning, student attitudes, student motivation, teaching method.

\footnotetext{
$\bar{*}$ Corresponding author.

E-mail address: dangmh@ vnu.edu.vn

https://doi.org/10.25073/2588-1167/vnuls.4341
} 


\title{
Phương pháp dạy học dự án thúc đẩy động cơ và thái độ học tập của sinh viên
}

\author{
Mai Hải Đăng* \\ Khoa Luật, Đại học Quốc gia Hà Nội, 144 Xuân Thủy, Cầu Giấy, Hà Nội \\ Nhận ngày 31 tháng 12 năm 2020 \\ Chỉnh sửa ngày 03 tháng 3 năm 2021; Chấp nhận đăng ngày 26 tháng 3 năm 2021
}

\begin{abstract}
Tóm tắt: Nghiên cứu này tìm hiểu phương pháp dạy học dự án (PBL) có ảnh hưởng như thế nào đến động cơ và thái độ của sinh viên khi nghiên cứu học phần Luật môi trường quốc tế. Mẫu nghiên cứu từ 100 sinh viên Khoa Luật, ĐHQGHN. Sử dụng thiết kế nghiên cứu hốn hợp: phương pháp nghiên cứu định tính và phương pháp nghiên cứu định lượng. Hai giả thuyết nghiên cứu được đưa ra: 1) Phương pháp dạy học dự án có làm tăng động cơ học tập của sinh viên? 2) Phương pháp dạy học dự án có cải thiện thái độ học tập của sinh viên? Kết quả nghiên cứu chỉ ra áp dụng phương pháp dạy học dự án thúc đẩy động cơ và thái độ học tập của sinh viên.
\end{abstract}

Tù khóa: Luật môi trường quốc tế, dạy học dự án, động cơ học tập, thái độ của sinh viên, phương pháp giảng dạy.

\section{Cơ sở lý luận về phương pháp dạy học dự án}

\subsection{Khái niệm phuoong pháp, phuơng pháp dạy hoc dư án}

Phương pháp (method) có thể hiểu là hệ thống các cách sử dụng để tiến hành một hoạt động nào đó [1]. Phương pháp cũng có thể hiểu là những kỹ thuật cụ thể dùng để thu thập dữ liệu, phân tích dữ liệu, kỹ thuật lựa chọn công cụ thu thập số liệu nhằm giải quyết những nhiệm vụ nhất định. Phương pháp dạy học có thể hiểu là những cách thức, đường hướng, hay phương hướng hành động để giải quyết vấn đề nhận thức của người học nhằm đạt được mục tiêu dạy học.

Có nhiều phương pháp dạy học. Một trong những phương pháp dạy học giáo viên có thể áp dụng là phương pháp dạy học dự án (projectbased learning). Có nhiều định nghĩa về phương pháp dạy học dự án. Bell (2010), phương pháp

\footnotetext{
"Tác giả liên hệ.

Địa chỉemail: dangmh@vnu.edu.vn

https://doi.org/10.25073/2588-1167/vnuls.4341
}

dạy học dự án là một phương pháp giảng dạy lấy người học làm trung tâm. Dưới sự giám sát, hướng dẫn của giáo viên, sinh viên đặt câu hỏi, tiến hành quá trình nghiên cứu [2]. Thomas (2000), phương pháp dạy học dự án là một mô hình tổ chức việc học tập xung quanh các dự án. Dự án là các nhiệm vụ phức tạp, dựa trên các câu hỏi hoặc vấn đề khó khăn, liên quan đến sinh viên trong các hoạt động thiết kế, giải quyết vấn đề, ra quyết định hoặc tiến hành điều tra; ở đó sinh viên được tự chủ kiểm soát thời gian và đưa ra kết quả là các sản phẩm cụ thể. Thomas (2000) năm đặc điểm của phương pháp dạy học dự án là: 1) tính trung tâm; 2) động lực thúc đẩy; 3) kiến tạo; 4) năng lực tự chủ trong học tập và 5) tính hiện thực [3]. Lê Khoa (2015), dạy học theo dự án là một phương pháp dạy học, trong đó học sinh dưới sự hướng dẫn của giáo viên tự lực giải quyết một nhiệm vụ học tập phức hợp, kết hợp giữa lí thuyết và thực hành, với hình thức làm việc chủ yếu là theo nhóm. Các nhóm tự xác định mục tiêu, lập kế hoạch và thực hiện dự án, tham gia kiểm tra quá trình thực hiện và đánh giá kết quả. Kết quả là các sản phẩm có thể giới thiệu, trình bày [4]. 
Trịnh Văn Biều và các cộng sự (2011), dạy học dự án là một hình thức dạy học hay phương pháp dạy học phức hợp, trong đó dưới sự hướng dẫn của giáo viên, người học tiếp thu kiến thức và hình thành kỹ năng thông qua việc giải quyết một bài tập tình huống (dự án) có thật trong đời sống, theo sát chương trình học, có sự kết hợp giữa lý thuyết với thực hành và tạo ra các sản phẩm cụ thể [5]. Nguyễn Thị Diệu Thảo (2009), dạy học theo dự án là một hình thức tổ chức dạy học, trong đó người học dưới sự chỉ đạo của giáo viên thực hiện một nhiệm vụ học tập phức hợp mang tính thực tiễ் với hình thức làm việc nhóm là chủ yếu. Nhiệm vụ này được thực hiện với tính tự lực cao trong toàn bộ quá trình học tập, tạo ra những sản phẩm có thể trình bày, giới thiệu [6]. Với phương pháp học này, người học sẽ phải làm việc theo nhóm và khám phá những vấn đề gắn liền với cuộc sống, sau đó sẽ thuyết trình trước lớp và chia sẻ những gì họ đã làm được trong dự án của mình.

Theo tác giả phương pháp dạy học dự án là phương pháp dạy học lấy sinh viên là trung tâm, dưới sự hướng dẫn của giáo viên, sinh viên tự lựa chọn giải quyết một vấn đề, lập kế hoạch giải quyết vấn đề đó với hình thức làm việc chủ yếu là theo nhóm. Các nhóm tự xác định mục tiêu, lập kế hoạch và thực hiện dự án, tham gia kiểm tra quá trình thực hiện và đánh giá kết quả. Kết quả là các sản phẩm cụ thể như mô hình, bức tranh hoặc bài thuyết trình theo sát chương trình học, có sự kết hợp giữa lý thuyết với thực hành và tạo ra các sản phẩm cụ thể.

\section{2. Động co, thái độ học tập của sinh viên}

Động cơ học tập là một trong những nhân tố kích thích, thúc đẩy tính tích cực, hứng thú học tập của người học nhằm đạt kết quả về nhận thức, phát triển nhân cách và hướng tới mục đích học tập đã đề ra. Harmer (1991), cho rằng động cơ là động lực bên trong thúc đẩy ai đó làm điều gì đó. Nếu chúng ta nghĩ rằng mục tiêu của chúng ta đáng làm và hấp dẫn đối với chúng ta, thì chúng ta cố gắng đạt được mục tiêu đó; điều này được gọi là hành động được thúc đẩy bởi động cơ [7]. Parsons, Hinson và Brown (2001), động cơ là một thành phần hoặc nhân tố quan trọng trong quá trình học tập. Để có được kiến thức thì việc học tập và động cơ có tầm quan trọng như nhau. Học tập giúp chúng ta có được những kiến thức, kỹ năng mới. Động cơ thúc đẩy hoặc kích thích chúng ta trong quá trình học tập [8]. Theo Gardner (1985), trong việc học ngôn ngữ thì Động cơ gồm có ba thành tố: nỗ lực, khát vọng và cảm xúc. Nỗ lực đề cập đến thời gian dành cho việc học ngôn ngữ và động lực của người học. Khát vọng cho biết mức độ, mong muốn của người học muốn thành thạo ngôn ngữ và cảm xúc có nghĩa là phản ứng xúc cảm của người học liên quan đến việc học ngôn ngữ [9].

Thái độ được hiểu là tồng thể những cảm xúc tích cực hay tiêu cực của cá nhân khi quan sát diễn biến của tình huống. Do đó, thái độ có thể được xem như là một tổng thể cảm nhận của một người về những hậu quả khác nhau của tình huống đó; và như vậy thái độ có thể được đo lường bằng cường độ của những hậu quả này [10]. Stark và cộng sự (2013) cho rằng thái độ là xu hướng phản ứng tích cực hoặc tiêu cực đối với một sự vật nhất định như một ý tưởng, đồ vật, con người hoặc tình huống [11]. Brown (1994) cho rằng có ba thành tố của thái độ đó là: Nhận thức, cảm xúc, và hành vi [12]. 1). Khía cạnh nhận thức đề cập đến những biểu hiện của niềm tin và ý tưởng hoặc ý kiến về đối tượng nào đó; về kiến thức, sự hiểu biết của người học sau quá trình nghiên cứu, học tập; 2). Khía cạnh cảm xúc mô tả những thay đổi về sở thích, thái độ của một người như thích hay không thích, đồng ý hay phản đối một điều gì đó; 3$)$. Khía cạnh hành vi đề cập đến cách một người cư xử và phản ứng trong các tình huống cụ thể.

\section{Các nghiên cứu về phương pháp dạy học dự án}

Một số nghiên cứu trước đây đã chỉ ra kết quả tích cực từ việc triển khai phương pháp dạy học dự án (PBL). Nghiên cứu (Bell, 2010), PBL hiệu quả hơn phương pháp học truyền thống, vì nó tạo ra nhiều khả năng, cơ hội để mỗi sinh viên có thể lựa chọn các chủ đề học tập học phù 
hợp với khả năng của mình. Sinh viên sẵn sàng đầu tư nhiều thời gian hơn cho việc chuẩn bị dự án của họ so với phương pháp học truyền thống. Legutke (1993), PBL thúc đẩy động cơ người học và tăng hứng thú học tập; sinh viên tích cực tìm kiếm tài liệu, dành nhiều thời gian hơn để thực hiện dự án của mình so với phương pháp truyền thống [13]. Becket và Miller (2006), PBL cho phép sinh viên tham gia vào quá trình tìm hiểu và khám phá các hiện tượng trong thực tế đời sống và phát triển khả năng sáng tạo của mình [14]. Williams (2017), PBL mang đến cơ hội cho sinh viên học các kỹ năng mềm, kỹ năng làm việc nhóm: giao tiếp, đàm phán, thuyết trình [15]. Neo \& Neo (2009), PBL thúc đẩy động cơ học tập của sinh viên, tăng khả năng tư duy phản biện, kỹ năng thuyết trình, kỹ năng giao tiếp và khả năng làm việc theo nhóm [16]. Özdemir, Yildiz và Yildiz (2015), PBL tạo ra bầu không khí lớp học thoải mái, sáng tạo; sinh viên cảm thấy công việc dự án là thú vị, tạo ra những cơ hội nhằm giúp người học thực hiện được những sở thích của mình, và tự mình đưa ra quyết định về câu trả lời hay tìm ra giải pháp cho các vấn đề trình bày trong dự án [17]. Naji Kortam và cộng sự (2018), PBL tạo cơ hội cho sinh viên phát triển các kỹ năng như: tư duy khoa học; làm việc nhóm; giao tiếp; sáng tạo; tự chủ, tự chịu trách nhiệm; sử dụng ngôn ngữ; công nghệ thông tin [18].

\section{Câu hỏi nghiên cứu}

Nghiên cứu dựa trên thiết kế nghiên cứu hỗn hợp, bằng việc sử dụng kết hợp phương pháp nghiên cứu định tính và phương pháp nghiên cứu định lượng. Hai câu hỏi nghiên cứu đã được đưa ra là:

1). Phương pháp dạy học dự án có làm tăng động cơ học tập của sinh viên?

2). Phương pháp dạy học dự án có cải thiện thái độ học tập của sinh viên?

Dựa trên hai câu hỏi nghiên cứu này, hai giả thuyết nghiên cứu đã được đưa ra:

1). Giải thuyết Ho, Phương pháp dạy học dự án không thúc đẩy động cơ và thái độ học tập của sinh viên.
2). Giải thuyết H1, Phương pháp dạy học dự án thúc đẩy động cơ và thái độ học tập của sinh viên.

\section{Phương pháp nghiên cứu}

\subsection{Thiết kế nghiên cưu}

Nghiên cứu sử dụng kết hợp phương pháp nghiên cứu định tính và phương pháp nghiên cứu định lượng. Phần định lượng dưới dạng bảng câu hỏi và phần định tính bao gồm một cuộc phỏng vấn bán cấu trúc đối với sinh viên, để thu thập thông tin từ sinh viên và dùng kết quả để kiểm tra chéo với những phát hiện của phần định lượng.

Mẫu nghiên cứu được tiến hành từ 100 sinh viên nghiên cứu học phần Luật môi trường quốc tế tại Khoa Luật, ĐHQGHN, chia làm hai lớp một lớp được giảng bằng phương pháp dạy học dự án (nhóm thực nghiệm), một lớp giảng theo phương pháp truyền thống (nhóm đối chứng) để đo lường và xác định phương pháp dạy học dự án có tác động như thế nào đến động cơ, thái độ và kết quả học tập của sinh viên Khoa Luật, ĐHQGHN.

Mô hình thiết kế nhóm đối chứng hậu kiểm định được thể hiện như sau:

$$
\begin{array}{ccc}
R & X & O 1 \text { (nhóm thực nghiệm) } \\
R & O 2 \text { (nhóm đối chứng) }
\end{array}
$$

Trong đó, $\mathrm{R}$ đại diện cho phân bổ ngẫu nhiên của các đối tượng thành các nhóm, $X$ đại diện cho các tác động được áp dụng đối với nhóm thực nghiệm và $\mathrm{O}$ đại diện cho quan sát sau kiểm định đối với biến phụ thuộc.

Hệ quả tác động $(\mathrm{E})$ được đánh giá là sự khác biệt trong kết quả hậu kiểm định giữa hai nhóm: $\mathrm{E}=(\mathrm{O} 1-\mathrm{O} 2)$.

\subsection{Công cu nghiên cứu}

Công cụ nghiên cứu gồm hai bảng câu hỏi cho phần định lượng; câu hỏi bán cấu trúc để phỏng vấn trong phần định tính. Sử dụng phần mềm SPSS 20.0 để phân tích và sử lý dữ liệu. 
Bảng câu hỏi về động cơ sử dụng để kiểm tra động cơ học tập của sinh viên khi nghiên cứu Luật môi trường quốc tế gồm 10 câu trên thang điểm Likert 5 mức $(1=$ hoàn toàn không đồng ý; 2 = không đồng ý; 3 = không có ý kiến; $4=$ đồng ý; $5=$ hoàn toàn đồng ý).

Bảng 1: Bảng câu hỏi về Động cơ học tập của sinh viên

\begin{tabular}{|c|l|c|c|c|c|c|}
\hline TT & \multicolumn{1}{|c|}{ Câu hỏi về Động co học tập } & $\begin{array}{c}\text { Hoàn } \\
\text { toàn } \\
\text { không } \\
\text { đồng ý } \\
(1)\end{array}$ & $\begin{array}{c}\text { Không } \\
\text { đồng ý } \\
(2)\end{array}$ & $\begin{array}{c}\text { Không } \\
\text { có ý } \\
\text { kiến } \\
(3)\end{array}$ & $\begin{array}{c}\text { Đồng ý } \\
(4)\end{array}$ & $\begin{array}{c}\text { Hoàn } \\
\text { toàn } \\
\text { đồng ý } \\
(5)\end{array}$ \\
\hline 1 & Tôi thích nghiên cứu Luật môi trường quốc tế. & & & & & \\
\hline 2 & $\begin{array}{l}\text { Tôi muốn biết những quy định của pháp luật quốc } \\
\text { tề về môi trường. }\end{array}$ & & & & & \\
\hline 3 & $\begin{array}{l}\text { Những kiến thức Luật môi trường quốc tế cần thiết } \\
\text { cho tương lai của tôi. }\end{array}$ & & & & & \\
\hline 4 & $\begin{array}{l}\text { Hiểu biết những kiến thức về Luâat môi trường } \\
\text { quốc tề là mục tiêu quan trọng của tổi. }\end{array}$ & & & & & \\
\hline 5 & $\begin{array}{l}\text { Tôi dành nhiều thời gian cho nghiên cứu Luật môi } \\
\text { trường quốc tế. }\end{array}$ & & & & & \\
\hline 6 & $\begin{array}{l}\text { Kiến thức về Luật môi trường quốc tế rất hữu ích } \\
\text { đối với tôi. }\end{array}$ & & & & & \\
\hline 7 & $\begin{array}{l}\text { Tôi cảm rất thấy hứng thú với không khí lớp học } \\
\text { Luật môi trường quốc tế. }\end{array}$ & & & & & \\
\hline 8 & $\begin{array}{l}\text { Tôi thích được học Luật môi trường quốc tế nhiều } \\
\text { hơn nữa. }\end{array}$ & & & & & \\
\hline 9 & $\begin{array}{l}\text { Tôi tin là sẽ vượt qua kỳ thi học phần Luật môi } \\
\text { trường quốc tế. }\end{array}$ & & & & & \\
\hline 10 & $\begin{array}{l}\text { Tôi thích cách giảng dạy của giáo viên Luật môi } \\
\text { trường quốc tế. }\end{array}$ & & & & & \\
\hline
\end{tabular}

Bảng câu hỏi về thái độ của sinh viên khi nghiên cứu Luật môi trường quốc tế gồm 30 câu trên thang điểm Likert 5 mức $(1=$ hoàn toàn không đồng ý; $2=$ không đồng ý; $3=$ không có ý kiến; $4=$ đồng ý; $5=$ hoàn toàn đồng ý).

Bảng 2: Bảng câu hỏi về thái độ học tập của sinh viên

\begin{tabular}{|c|l|c|c|c|c|c|}
\hline TT & \multicolumn{1}{|c|}{ Câu hỏi về Thái độ học tập } & $\begin{array}{c}\text { Hoàn } \\
\text { toàn } \\
\text { không } \\
\text { đồng } \\
\text { ý (1) }\end{array}$ & $\begin{array}{c}\text { Không } \\
\text { đồng ý } \\
(2)\end{array}$ & $\begin{array}{c}\text { Không } \\
\text { có ý } \\
\text { kiến } \\
(3)\end{array}$ & $\begin{array}{c}\text { Đồng } \\
\text { ý } \\
(4)\end{array}$ & $\begin{array}{c}\text { Hoàn } \\
\text { toàn } \\
\text { đồng } \\
\text { ý } \\
(5)\end{array}$ \\
\hline & Khía cạnh nhận thức của thái độ & & & & & \\
\hline 1 & $\begin{array}{l}\text { Những kiến thức về Luật môi trường quốc tế giúp tôi } \\
\text { hiếu biêt thêm những quy định của pháp luật quốc tế. }\end{array}$ & & & & & \\
\hline 2 & Tôi thu được nhiều kiến thức và hiều biết hơn khi & & & & & \\
\hline
\end{tabular}




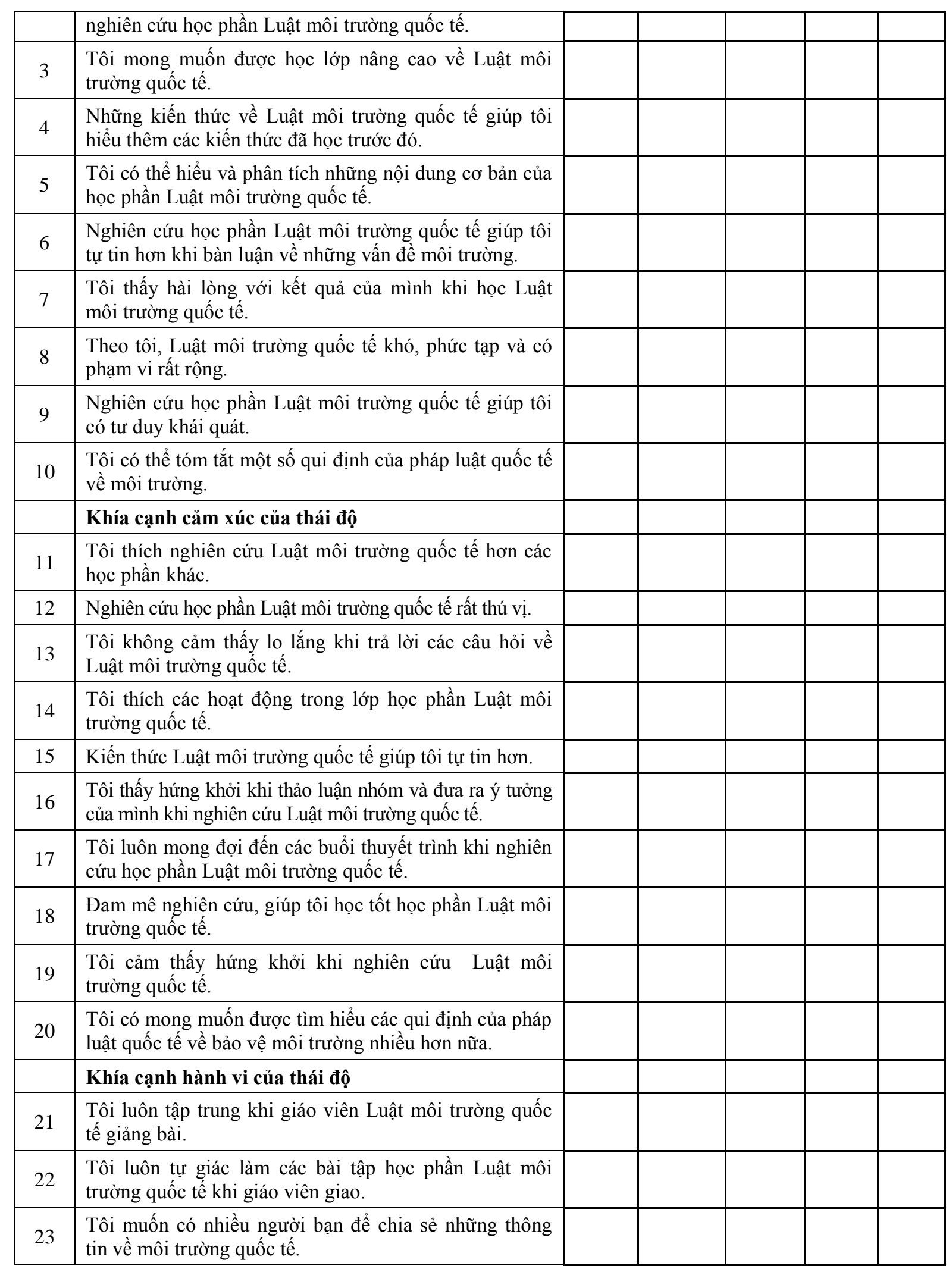




\begin{tabular}{|c|l|l|l|l|l|l|}
\hline 24 & $\begin{array}{l}\text { Học phần Luật môi trường quốc tế giúp tôi có mối quan } \\
\text { hệ tốt với các bạn cưng lớp. }\end{array}$ & & & & & \\
\hline 25 & $\begin{array}{l}\text { Tôi thích đưa ra ý kiến và phát biểu trong các buổi học } \\
\text { Luật môi trường quốc tế. }\end{array}$ & & & & & \\
\hline 26 & $\begin{array}{l}\text { Khi tôi nghe các bạn thuyết trình về chủ đề của nhóm, } \\
\text { tôi mong muốn được thuyết trình giống các bạn. }\end{array}$ & & & & & \\
\hline 27 & $\begin{array}{l}\text { Nghiên cứu học phần Luật môi trường quốc tế giúp tôi } \\
\text { tự tin hơn trong thể hiện bản thân. }\end{array}$ & & & & & \\
\hline 28 & $\begin{array}{l}\text { Tôi không cảm thấy bối rối khi phải thuyết trình những } \\
\text { nội dung liên quan đến Luật môi trường quốc tế. }\end{array}$ & & & & & \\
\hline 29 & Tôi rất thoải mái trong giờ học Luật môi trường quốc tế. & & & & & \\
\hline 30 & $\begin{array}{l}\text { Nghiên cứu học phần Luật môi trường quốc tế giúp tôi } \\
\text { hoàn thiện nhân cách của mình. }\end{array}$ & & & & & \\
\hline
\end{tabular}

Câu hỏi bán cấu trúc: Năm câu đầu tập trung vào các hoạt động của sinh viên trong lớp học, về cảm giác của sinh viên khi học theo PBL và cảm nhận của sinh viên liên quan đến nhiệm vụ mà giảng viên giao cho họ. Năm câu tiếp theo về khía cạnh nhận thức của sinh viên khi học theo PBL. Năm câu cuối là tập trung vào các khía cạnh hành vi của sinh viên sau khi nghiên cứu học phần Luật môi trường quốc tế theo PBL.

\subsection{Các bước tiến hành}

Để xác định có sự khác biệt về thái độ và động cơ của các sinh viên khi áp dụng PBL hay không, các sinh viên được chia làm hai lớp một lớp được giảng bằng phương pháp dạy học dự án (nhóm thực nghiệm), một lớp giảng theo phương pháp truyền thống (nhóm đối chứng) để đo lường và xác định phương pháp dạy học dự án có tác động như thế nào đến động cơ, thái độ và kết quả học tập của sinh viên tại Khoa Luật, ĐHQGHN

Sinh viên trong nhóm thực nghiệm được sử dụng phương pháp dạy học dự án khi nghiên cứu Luật môi trường quốc tế trong 15 tuần theo các bước sau.

i). Giáo viên giới thiệu về $\mathrm{PBL}$ và đặc điểm của PBL, chia nhóm (5-7 sinh viên/ nhóm).

ii). Các nhóm thảo luận và chọn chủ đề nghiên cứu có liên quan đến nội dung học phần Luật môi trường quốc tế. iii). Giáo viên hướng dẫn và sinh viên xây dựng đề cương, tự quyết định sản phẩm của nhóm, phân công công việc trong nhóm và lựa chọn hình thức công bố sản phẩm cuối cùng. Hoàn thiện đề cương.

iv). Gửi Đề cương cho giáo viên góp ý.

v). Thực hiện dự án, sinh viên tự nghiên cứu tài liệu, tìm kiếm thông tin, tổng kết, thảo luận và viết báo cáo.

vi). Các nhóm thuyết trình trong ba buổi học, mỗi nhóm 15 đến 20 phút.

vii). Tổng hợp kết quả, đánh giá dự án, rút kinh nghiệm.

Kết thúc môn học, giáo viên cho cả hai lớp cùng hoàn thành bảng câu hỏi về động cơ và thái độ. Người tham gia được yêu cầu trả lời trung thực tất cả các mục của bảng câu hỏi, đưa ra nhận định của riêng mình về động cơ và thái độ khi nghiên cứu Luật môi trường quốc tế. Các sinh viên được thông báo bảng câu hỏi không ảnh hưởng đến điểm số của họ trong học phần Luật môi trường quốc tế.

Phỏng vấn: Sau khi hoàn thành bảng hỏi, tiến hành phỏng vấn 15 sinh viên trong nhóm thực nghiệm, mỗi cuộc phỏng vấn 15 phút, trước khi phỏng vấn nói với sinh viên mục đích của cuộc phỏng vấn nhằm tạo không khí vui vẻ, hợp tác. Câu trả lời chỉ để sử dụng cho mục đích nghiên cứu. 


\section{Kết quả và bàn luận}

Dũ liệu điều tra thu được được sử dụng phần mềm SPSS 20.0 để phân tích và xử lý. Kết quả phân tích dữ liệu trên khía cạnh: Động cơ, thái độ của sinh viên khi học theo phương pháp dạy học dự án học phần Luật môi trường quốc tế được thể hiện ở các bảng sau:

\section{1. Ở khía cạh động $c o$}

Kết quả kiểm định độ tin cậy thang đo Cronbach's Alpha đối với khía cạnh động cơ là: 0,791 , điều này cho thấy thang đo lường sử dụng tốt và độ tin cậy tương đối cao. Thực hiện kiểm định Independent -Sample T- Test, để so sánh sự khác biệt về động cơ giữa nhóm thực nghiệm và nhóm đối chứng kết quả được thể hiện bảng sau:

Bảng 3: Sự khác biệt về động cơ giữa nhóm thực nghiệm (nhóm 2) và nhóm đối chứng (nhóm 1)

Group Statistics

\begin{tabular}{|c|c|c|c|c|c|}
\hline & Nhóm & $\mathrm{N}$ & Mean & $\begin{array}{c}\text { Std. } \\
\text { Deviation }\end{array}$ & $\begin{array}{c}\text { Std. Error } \\
\text { Mean }\end{array}$ \\
\hline \multirow{2}{*}{ Động cơ } & 1 & 50 & 3.644000 & .5147458 & .0727961 \\
\cline { 2 - 6 } & 2 & 50 & 4.004000 & .3697545 & .0522912 \\
\hline
\end{tabular}

Independent Samples Test

\begin{tabular}{|c|c|c|c|c|c|c|c|c|c|c|}
\hline & \multicolumn{2}{|c|}{$\begin{array}{l}\text { Levene's Test } \\
\text { for Equality } \\
\text { of Variances }\end{array}$} & \multicolumn{7}{|c|}{ t-test for Equality of Means } \\
\hline & & \multirow[t]{2}{*}{$\mathrm{F}$} & \multirow[t]{2}{*}{ Sig. } & \multirow[t]{2}{*}{$\mathrm{T}$} & \multirow[t]{2}{*}{ df } & \multirow{2}{*}{$\begin{array}{l}\text { Sig.(2- } \\
\text { tailed) }\end{array}$} & \multirow{2}{*}{$\begin{array}{c}\text { Mean } \\
\text { Difference }\end{array}$} & \multirow{2}{*}{$\begin{array}{l}\text { Std. Error } \\
\text { Difference }\end{array}$} & \multicolumn{2}{|c|}{$\begin{array}{l}95 \% \text { Confidence } \\
\text { Interval of the } \\
\text { Difference }\end{array}$} \\
\hline & & & & & & & & & Lower & Upper \\
\hline \multirow{2}{*}{$\begin{array}{l}\text { Động } \\
\text { cơ }\end{array}$} & $\begin{array}{l}\text { Equal } \\
\text { variances } \\
\text { assumed } \\
\end{array}$ & 3.444 & .066 & -4.016 & 98 & .000 & -.3600000 & .0896305 & -.5378689 & .1821311 \\
\hline & $\begin{array}{l}\text { Equal } \\
\text { variances } \\
\text { not } \\
\text { assumed }\end{array}$ & & & -4.016 & 88.935 & .000 & -.3600000 & .0896305 & -.5380958 & -.1819042 \\
\hline
\end{tabular}

Nhìn vào kết quả bảng trên ta thấy, kết quả Levene's Test ở khía cạnh động cơ Sig = $0,66>0,05$, nghĩa là phương sai của nhóm thực nghiệm và nhóm đối chứng không khác nhau. Giá trị Sig. (2-tailed) $=0.00<0,05$ nghĩa là có sự khác biệt về động cơ của sinh viên trong nhóm thực nghiệm và nhóm đối chứng, trong đó, nhóm thực nghiệm có trung bình cộng
Mean=4,004 và nhóm đối chứng có trung bình cộng Mean=3,644.

Căn cứ vào kết quả này, chúng ta bác bỏ giả thuyết Ho và chấp nhận giả thuyết $\mathrm{H} 1$ phương pháp dạy học dự án có làm thay đổi động cơ học tập của sinh viên và có sự khác biệt đáng kể về động cơ của sinh viên khi áp dụng phương pháp dạy học dự án trong học phần Luật môi 
trường quốc tế giữa nhóm thực nghiệm và nhóm đối chứng.

\section{2. Ở khía cạh Thái độ}

Kết quả kiểm định độ tin cậy thang đo Cronbach's Alpha đối với lĩnh vực nhận thức, cảm xúc và hành vi lần lượt là: 0,$819 ; 0,839$ và
0,847 , điều này cho thấy thang đo lường sử dụng tốt và độ tin cậy tương đối cao.

Thực hiện kiểm định Independent - Sample T- Test, để so sánh sự khác biệt về thái độ giữa nhóm thực nghiệm và nhóm đối chứng kết quả được thể hiện bảng sau:

Bảng 4: Sự khác biệt về thái độ giữa nhóm thực nghiệm (nhóm 2) và nhóm đối chứng (nhóm 1).

Group Statistics

\begin{tabular}{|l|c|c|c|c|c|}
\hline & Nhóm & $\mathrm{N}$ & Mean & $\begin{array}{c}\text { Std. } \\
\text { Deviation }\end{array}$ & $\begin{array}{c}\text { Std. Error } \\
\text { Mean }\end{array}$ \\
\hline Nhận thức & 1 & 50 & 3.558000 & .4394291 & .0621447 \\
\hline & 2 & 50 & 4.020000 & .6983947 & .0987679 \\
\hline Cảm xúc & 1 & 50 & 3.630000 & .5075954 & .0717848 \\
\hline & 2 & 50 & 4.116000 & .4156922 & .0587878 \\
\hline Hành vi & 1 & 50 & 3.634000 & .4666905 & .0660000 \\
\hline & 2 & 50 & 4.134000 & .4942981 & .0699043 \\
\hline
\end{tabular}

Independent Samples Test

\begin{tabular}{|c|c|c|c|c|c|c|c|c|c|c|}
\hline & & \multicolumn{2}{|c|}{$\begin{array}{c}\text { Levene's Test } \\
\text { for Equality of } \\
\text { Variances }\end{array}$} & \multicolumn{7}{|c|}{ t-test for Equality of Means } \\
\hline & & \multirow[t]{2}{*}{$\mathrm{F}$} & \multirow[t]{2}{*}{ Sig. } & \multirow[t]{2}{*}{$\mathrm{T}$} & \multirow[t]{2}{*}{ Df } & \multirow[t]{2}{*}{$\begin{array}{l}\text { Sig. }(2- \\
\text { tailed) }\end{array}$} & \multirow[t]{2}{*}{$\begin{array}{c}\text { Mean } \\
\text { Difference }\end{array}$} & \multirow[t]{2}{*}{$\begin{array}{l}\text { Std. Error } \\
\text { Difference }\end{array}$} & \multicolumn{2}{|c|}{$\begin{array}{c}95 \% \text { Confidence Interval } \\
\text { of the Difference }\end{array}$} \\
\hline & & & & & & & & & Lower & Upper \\
\hline \multirow[b]{2}{*}{$\begin{array}{l}\text { Nhận } \\
\text { thức }\end{array}$} & $\begin{array}{l}\text { Equal } \\
\text { variances } \\
\text { assumed }\end{array}$ & 5.774 & .018 & -3.959 & 98 & .000 & -.4620000 & .1166922 & -.6935718 & -.2304282 \\
\hline & $\begin{array}{l}\text { Equal } \\
\text { variances } \\
\text { not } \\
\text { assumed }\end{array}$ & & & -3.959 & 82.541 & .000 & -.4620000 & .1166922 & -.6941151 & -.2298849 \\
\hline \multirow{2}{*}{$\begin{array}{l}\text { Cảm } \\
\text { xúc }\end{array}$} & $\begin{array}{l}\text { Equal } \\
\text { variances } \\
\text { assumed }\end{array}$ & 1.987 & .162 & -5.238 & 98 & .000 & -.4860000 & .0927850 & -.6701289 & -.3018711 \\
\hline & $\begin{array}{l}\text { Equal } \\
\text { variances } \\
\text { not } \\
\text { assumed }\end{array}$ & & & -5.238 & 94.334 & .000 & -.4860000 & .0927850 & -.6702183 & -.3017817 \\
\hline \multirow{2}{*}{$\begin{array}{l}\text { Hành } \\
\text { vi }\end{array}$} & $\begin{array}{l}\text { Equal } \\
\text { variances } \\
\text { assumed }\end{array}$ & .289 & .592 & -5.201 & 98 & .000 & -.5000000 & .0961385 & -.6907837 & -.3092163 \\
\hline & $\begin{array}{l}\text { Equal } \\
\text { variances } \\
\text { not } \\
\text { assumed }\end{array}$ & & & -5.201 & 97.678 & .000 & -.5000000 & .0961385 & -.6907916 & -.3092084 \\
\hline
\end{tabular}

Nhìn vào kết quả bảng trên ta thấy, kết quả Levene's Test trên các khía cạnh: i) Khía cạnh nhận thức $\mathrm{Sig}=0,18>0,05$, nghĩa là phương sai của nhóm thực nghiệm và 
nhóm đối chứng không khác nhau. Giá trị Sig. (2-tailed) $=0.00<0,05$ nghĩa là có sự khác biệt về nhận thức của sinh viên trong nhóm thực nghiệm và nhóm đối chứng, trong đó nhóm thực nghiệm có trung bình cộng Mean=4,020, nhóm đối chứng có trung bình cộng Mean= 3,558 ;

ii) Khía cạnh cảm xúc $\operatorname{Sig}=0,16>0,05$, nghĩa là phương sai của hai nhóm không khác nhau. Giá trị Sig. (2-tailed) $=0.00<0,05$ nghĩa là có sự khác biệt về cảm xúc của sinh viên giữa nhóm thực nghiệm và nhóm đối chứng, trong đó nhóm thực nghiệm có trung bình cộng Mean $=4,116$, nhóm đối chứng có trung bình cộng Mean=3,630;

iii) Khía cạnh hành vi $\mathrm{Sig}=0,59>0,05$, nghĩa là phương sai của hai nhóm không khác nhau. Giá trị Sig. $(2$-tailed $)=0.00<0,05$ nghĩa là có sự khác biệt trong hành vi của sinh viên nhóm thực nghiệm và nhóm đối chứng, trong đó nhóm thực nghiệm có trung bình cộng Mean=4,134, nhóm đối chứng có trung bình cộng Mean=3,634.

Như vậy chúng ta bác bỏ giả thuyết Ho và chấp nhận giả thuyết H1 phương pháp dạy học dự án làm thay đổi thái độ học tập của sinh viên và có sự khác biệt đáng kể về thái độ của sinh viên khi nghiên cứu học phần Luật môi trường quốc tế, điều này cũng phù hợp với các nghiên cứu trước đây là sinh viên học theo phương pháp dạy học dự án có xu hướng phát triển thái độ tích cực hơn so với học theo phương pháp truyền thống (Baş \& Beyhan, 2010; Kaldi et al., 2011).

\subsection{Kết quả phỏng vấn}

Hầu hết sinh viên hài lòng khi được học theo phương pháp dạy học dự án và cảm thấy thú vị và rất có ý nghĩa khi học theo phương pháp này vì một số lý do sau: Được tự chủ trong việc học tập của mình, tự do nghiên cứu những chủ đề mình yêu thích, phương pháp dạy học dự án nâng cao khả năng làm việc nhóm, thuyết trình, tích cực tham gia đặt câu hỏi, tranh luận với nhóm khác; phát triển khả năng ứng dụng công nghệ thông tin; phát triển khả năng tư duy sáng tạo, tìm tòi cái mới, phát triển các kỹ năng mềm,...

Cũng tồn tại một số vấn đề như: sinh viên không cảm thấy thích thú khi phải làm việc theo nhóm, vì một số người không làm theo kế hoạch, ảnh hưởng tiển độ chung; một số cho rằng một số bạn quá tích cực làm hết công việc của người khác; $\mathrm{PBL}$ cần nhiều thời gian để đọc, để thực hiện xong một dự án mất quá nhiều thời gian, không đủ thời gian để hoàn thành; hạn chế về khả năng ứng dụng công nghệ thông tin; một số sinh viên cho rằng buộc phải thực hiện vì sợ giáo viên cho điểm thấp, họ cũng không thích học theo PBL.

\section{Kết luận}

Nghiên cứu đã tóm tắt về quá trình triển khai áp dụng phương pháp dạy học dự án trong giảng dạy học phần Luật môi trường quốc tế tại Khoa Luật, ĐHQGHN. Qua phản hồi của sinh viên, và quan sát trực tiếp trong các buổi trên lớp, tác giả nhận thấy, việc triển khai PBL làm tăng động cơ học tập của sinh viên và giúp sinh viên có thái độ tích cực hơn đối với việc nghiên cứu học phần Luật môi trường quốc tế. Áp dụng PBL tạo ra được những thay đổi đáng kể trong quá trình dạy học phần Luật môi trường quốc tế tại Khoa Luật, ĐHQGHN. Học tập theo PBL sinh viên có hứng thú hơn, thích chia sẻ ý tưởng và thảo luận nhóm nhiều hơn, phát huy tính tự giác trong học tập, phát triển được các kỹ năng mềm và quan tâm hơn tới môn học nhiều hơn so với phương pháp dạy học truyền thống. Những kết quả nghiên cứu áp dụng PBL đối với học phần này có thể giúp đưa ra khuyến nghị cho việc áp dụng PBL ở các học phần khác tại Khoa Luật, ĐHQGHN và các sinh viên học luật nói chung.

\section{Lời cảm ơn}

Bài viết này được thực hiện trong khuôn khổ đề tài nghiên cứu khoa học cấp Đại học Quốc gia Hà Nội, đề tài "Nghiên cứu ứng dụng 
phương pháp dạy học dự án trong giảng dạy học phần Luật môi trường quốc tế tại Khoa Luật, Đại học Quốc gia Hà Nội”, Mã đề tài QG.20.03 do TS. Mai Hải Đăng làm chủ nhiệm.

\section{Tài liệu tham khảo}

[1] Từ điển Tiếng Việt, Viện Ngôn ngữ, NXB Đà Nẵng 2003.

[2] S. Bell, Project-based learning for the 21st century: Skills for the future, The Clearing House 2010, 83 (2), 39-43.

[3] Thomas, J.W, A review of research on projectbased learning. Autodesk Foundation, 2000, http://www.bobpearlman.org/BestPractices/PBL_ Research.pdf.

[4] Lê Khoa, Vận dụng phương pháp dạy học theo dụ án trong dạy học kiến thức về sản xuất và sử dụng điện năng cho học sinh Trung học phổ thông, Luận án tiến sĩ Khoa học Giáo dục, Đại học Thái Nguyên, 2015.

[5] Trịnh Văn Biều, Phan Đồng Châu Thủy, Trịnh Lê Hồng Phương. (2011). Dạy học theo dự án - từ lí luận đến thực tiễn. Tạp chí Khoa học, Trường Đại học Sư phạm TPHCM, số 28.

[6] Nguyễn Thị Diệu Thảo, Dạy học theo dự án và vận dụng trong đào tạo giáo viên Trung học cơ sở môn công nghệ, Luận án Tiến sĩ giáo dục học, Trường Đại học Sư phạm Hà Nội, 2009.

[7] J. Harmer,. The practice of English language teaching, London: Longman, 1991.

[8] R. Parsons, S. Hinson, D. Brown Educational psychology: practitioner-researcher models of teaching. University of Virginia: Wadsworth Thomson Learning, 2001.
[9] R.C. Gardner, Social psychology and second language learning: The role of attitudes and motivation London: Edward Arnold Publishers. 1985.

[10] J. Mc Millan, Research in Education: A Conceptual Introduction 5th Edition, 2001, Pearson.

[11] T. Stark, A. Flache, Generalization of positive and negative attitudes toward individuals to outgroup attitudes, 2013.

[12] H. Brown, No Title. New York: Prentice Hall Regence, 1994.

[13] M. Legutke, Room to talk: Experiential learning in the foreign language classroom, Die Neueren Sprachen, 1993, 92(4), 306-33.

[14] G. Becket, P. Miller, (2006). Project-Based Second and Foreign Language Education: Past, Present, and Future, Research in Second Language Learning.

[15] S. Williams, Investigating the allocation and corroboration of individual grades for project-based learning. Studies in Educational Evaluation, 2017, 53 (February), 1-9.. Link: https://doi.org/10.1016/j.stueduc.2016.10.00912j

[16] M. Neo \& T. Neo, Engaging students in multimedia-mediated constructivist learningStudents' perceptions. Educational technology \& Society. Educational Technology \& Society, 2009 12(20), 254- 66.

[17] A. S. Özdemir, F. Yildiz, S. G. Yildiz, The effect of project based learning in "Ratio, Proportion and Percentage" unit on mathematics success and attitude. European Journal of Science and Mathematics Education, 2015, 3(1), 1-13.

[18] Naji Kortam, How Project-Based learning promotes 7th grade students' motivation and attitudes towards studying biology. 